\title{
Effects of an Aorticopulmonary Shunt on Lung Fluid Balance in the Young Lamb
}

\author{
TIMOTHY F. FELTES AND THOMAS N. HANSEN \\ Divisions of Pediatric Cardiology and Neonatology, Department of Pediatrics, Baylor College of Medicine, \\ Houston, Texas 77030
}

\begin{abstract}
We studied the effects of increased pulmonary blood flow on lung fluid balance in seven chronically instrumented lambs $(18 \pm 1 \mathrm{~d})$ with surgically created aorticopulmonary shunts. We measured mean pulmonary arterial and left atrial pressure (LAP), pulmonary blood flow, lung lymph flow, and lymph $\left(C_{L}\right)$ and plasma $\left(C_{P}\right)$ protein concentration with the shunt closed and opened. With the shunt partially open, a $35 \%$ increase in pulmonary blood flow resulted in an increase in pulmonary arterial pressure (15.5 \pm 1 to $19.5 \pm 1$ torr $)$ and LAP $(2.0 \pm 0.5$ to $3.5 \pm 0.5$ torr). Lung lymph flow nearly doubled (1.53 \pm 0.28 to $2.83 \pm 0.52 \mathrm{~mL} / \mathrm{h}$ ) whereas the $\mathrm{C}_{\mathrm{L}}$ decreased $(4.1 \pm 0.1$ to $3.4 \pm 0.1 \mathrm{~g} / \mathrm{dL})$ resulting in a decrease in the $C_{L} / C_{P}$ ratio $(0.67 \pm 0.01$ to $0.58 \pm 0.01)$. With the shunt fully open, pulmonary blood flow increased $65 \%$ over baseline, pulmonary arterial pressure increased from $16.5 \pm$ 2.0 to $26.5 \pm 5$ torr, and LAP increased from $1.5 \pm 0.5$ to $6.5 \pm 2.0$ torr. Lung lymph flow increased $(1.1 \pm 0.2$ to $3.1 \pm 0.2 \mathrm{~mL} / \mathrm{h})$ whereas $C_{\mathrm{L}}(4.1 \pm 0.1$ to $3.1 \pm 0.3 \mathrm{~g} / \mathrm{dL})$ and $C_{L} / C_{P}(0.66 \pm 0.02$ to $0.51 \pm 0.05)$ decreased. All changes were statistically significant $(p<0.05)$. When the effects of increased LAP on lung fluid balance (partial mitral valve obstruction) were tested in five additional lambs, an identical change in LAP as seen in lambs with partially open shunts $(2.5 \pm 0.5$ to $4.0 \pm 0.5$ torr $)$ resulted in only a $20 \%$ increase in lung lymph flow and a small decrease in the $C_{\downarrow} / C_{P}$ ratio $(0.61 \pm 0.02$ to $0.57 \pm 0.02)$, whereas pulmonary blood flow did not change. We conclude that in the newborn lamb increased pulmonary blood flow from a large central shunt increased the rate of transvascular fluid filtration in the lung by increasing filtration pressure. This increase could not be explained simply on the basis of a change in left atrial pressure and implies that resistance downstream from fluid filtering sites is relatively fixed. (Pediatr Res 26:94-97, 1989)
\end{abstract}

The infant with patent ductus arteriosus develops pulmonary dysfunction presumably as a result of increased fluid filtration secondary to an increase in the microvascular filtration pressure. Historically, the increase in filtration pressure has been thought to be the result of left ventricular volume overload and left atrial hypertension (1). However, infants, and particularly premature infants, may develop pulmonary dysfunction without evidence of left heart failure suggesting that increases in blood flow can increase filtration pressure directly $(2-5)$.

The purpose of our experiments was to test the hypothesis that

Received March 27, 1989; accepted April 19, 1989.

Correspondence Timothy F. Feltes, M.D., Assistant Professor of Pediatrics and Medicine, Division of Pediatric Cardiology, Texas Children's Hospital, 6621 Fannin, Houston, TX 77030. in the newborn lamb, increases in pulmonary blood flow would increase lung fluid filtration by increasing filtration pressure independent of changes in left atrial pressure.

\section{MATERIALS AND METHODS}

We operated on all lambs during the 1st wk after birth using halothane and nitrous oxide anesthesia. From a hindlimb cutdown we inserted polyvinyl catheters into a peripheral artery and vein and advanced them into the descending aorta and inferior vena cava, respectively. We also inserted a $3.5 \mathrm{Fr}$ thermistor wire (American Edwards, Anasco, PR) into a peripheral artery by separate cutdown and advanced it into the descending aorta.

Next, through a left thoracotomy, we placed catheters directly into the left atrium and pulmonary artery and isolated and divided the ductal remnant. We tunneled all catheters to the left chest and covered them with a vinyl pouch sewn to the skin.

For lambs in which pulmonary blood flow was to be increased, we surgically implanted a $6 \mathrm{~mm}$ woven Dacron graft (Meadox Medicals Inc., Oakland, NJ) between the aorta and main pulmonary artery at the time of the left thoracotomy. We placed a balloon-tipped catheter directly into the graft and an external occluder around its aortic end so that partial or even complete shunt occlusion could be achieved noninvasively.

For lambs in whom left atrial pressure was to be increased, we inserted an 8 Fr Foley catheter into the left atrium at the time of the left thoracotomy and tunneled its injection port out of the chest along with the catheters. Inflation of the balloon with saline resulted in partial occlusion of the mitral orifice and increased left atrial pressure.

Then 3 days later we performed a right thoracotomy to cannulate the efferent duct of the caudal mediastinal lymph node. First, we resected the systemic contributions to the node by dividing the lower portion of the node and cauterizing obvious lymphatic channels on the diaphragm and esophagus. Then we inserted a polyvinyl catheter, impregnated with heparin (TDMAC Processing, Polyscience, Warrington, PA) into the efferent duct. Finally, we placed a $3 \times 3$ silicon balloon (Silastic, Down Corning, Midland, MI) in the pleural space for subsequent measurement of pleural pressure.

We returned the lambs to their mothers for warmth and nutrition and allowed them to recover for at least $3 \mathrm{~d}$ before starting experiments.

We studied all lambs as they rested unsedated in a sling that did not interfere with respiratory efforts. We measured vascular and pleural pressures at frequent intervals using Statham strain gauge monometers (Statham Instruments, Inc., Hato Rey, PR) and a Grass 7D 8-channel amplifier/recorder (Grass Instruments, Quincy, MA) and obtained heart rate and respiratory rate from phasic pressure tracings. The zero reference for vascular pressures was the level of the left atrium; for measurement of pleural pressure, zero reference was atmospheric pressure. We measured pulmonary blood flow using the indicator dilution method with 
iced saline as the indicator and a Gould Statham SP1425 computer (Statham Instruments, Inc., Hato Rey, PR). We calculated pulmonary vascular resistance by dividing the difference between mean pulmonary arterial and left atrial pressures by the pulmonary blood flow.

In all experiments, we collected samples of lung lymph every $30 \mathrm{~min}$ and measured their volume to the nearest $0.01 \mathrm{~mL}$. In addition, we obtained samples of aortic blood every hour. We spun samples of blood and lymph and estimated the total protein content of the supernates by measuring total solids using a refractometer.

We studied the effects of increased pulmonary blood flow on lung fluid filtration in seven lambs with an average age of 18 days $( \pm 1)$ and wt of $6.6 \mathrm{~kg}( \pm 0.3)$. After collecting lymph during a 2- to 3-h baseline period with the shunt fully occluded, we partially opened the shunt and continued to collect lymph until a second 2- to 3-h steady state was achieved.

Next, we attempted to increase pulmonary blood flow further by deflating the occluding balloon completely. Lymph was collected until a final steady state was achieved.

In addition, we studied five lambs to test the effect of increased left atrial pressure alone on lung fluid filtration. These lambs were $14 \mathrm{~d}( \pm 2)$ old and weighed $7.2 \mathrm{~kg}( \pm 0.4)$. After a 2 - to 3 -h baseline period, we increased the left atrial pressure of these lambs by partial inflation of the Foley catheter and collected lymph until a second 2- to 3-h steady state was achieved.

Statistical analysis. Results are expressed as the mean \pm SEM in both text and tables. We used a paired $t$ test to compare values obtained during baseline periods with those obtained in lambs with open shunts or raised left atrial pressure. We regarded a $p$ $<0.05$ as an indication of a significant change (5).
RESULTS

Pulmonary blood flow increased $35 \%$ in our lambs when the shunt was partially opened (Table 1). This increase in flow resulted in an increase in mean pulmonary arterial pressure of 4 torr and mean left atrial pressure of 1.5 torr. Pulmonary vascular resistance did not change significantly.

Despite the relatively small change in left atrial pressure, lung lymph flow nearly doubled (Table 1) and the lymph protein concentration decreased. Plasma protein concentration remained unchanged so that lymph:plasma protein ratio decreased.

No significant changes occurred in heart rate or arterial blood gas tensions with opening the shunt except for arterial $\mathrm{pH}$ which decreased a trivial amount (Table 1). Mean central venous (3.5 \pm 0.5 to $4.0 \pm 0.5$ torr), aortic ( $78 \pm 3$ to $79 \pm 5$ torr) and pleural $(-0.5 \pm 0.5$ to $-1.0 \pm 0.6$ torr) pressures, respiratory rate $(61 \pm$ 8 to $61 \pm 8 / \mathrm{min})$ and hematocrit $(26 \pm 1$ to $26 \pm 1)$ were also not affected.

By further deflation of the ballon occluder, a second steady state at higher pulmonary blood flow was achieved in three of the lambs (Table 1). In these animals, pulmonary blood flow increased $65 \%$ over baseline and pulmonary arterial and left atrial pressures increased (10 and 5 torr, respectively). Lung lymph flow nearly tripled, lymph protein concentration decreased $(24 \%)$, and lymph:plasma protein concentration ratio decreased $(23 \%)$.

In our second group of lambs, inflating the left atrial balloon catheter increased left atrial pressure by an amount identical to that in lambs with an open shunt (1.5 torr, Table 2). Pulmonary arterial pressure also increased 1.5 torr, but pulmonary blood flow and pulmonary vascular resistance did not change. In

Table 1. Lung fluid filtration in lambs with aorticopulmonary shunt*

\begin{tabular}{|c|c|c|c|c|c|c|c|c|c|c|c|c|}
\hline Shunt & $\begin{array}{c}\mathrm{PBF} \\
(\mathrm{L} / \mathrm{min})\end{array}$ & $\begin{array}{l}\text { PAP } \\
\text { (torr) }\end{array}$ & $\begin{array}{l}\text { LAP } \\
\text { (torr) }\end{array}$ & $\begin{array}{c}\text { PVR } \\
\text { (torr } / \mathrm{L} / \mathrm{min} \text { ) }\end{array}$ & $\begin{array}{c}\dot{\mathrm{Q}}_{\mathrm{L}} \\
(\mathrm{mL} / \mathrm{h})\end{array}$ & $\begin{array}{c}\mathrm{C}_{\mathrm{L}} \\
(\mathrm{g} / \mathrm{dL})\end{array}$ & $\begin{array}{c}\mathrm{C}_{\mathrm{P}} \\
(\mathrm{g} / \mathrm{dL})\end{array}$ & $\mathrm{C}_{\mathrm{L}} / \mathrm{C}_{\mathrm{P}}$ & $\begin{array}{c}\text { HR } \\
(\mathrm{bpm})\end{array}$ & $\mathrm{pH}$ & $\begin{array}{l}\mathrm{PaO}_{2} \\
\text { (torr) }\end{array}$ & $\begin{array}{l}\mathrm{PaCO}_{2} \\
\text { (torr) }\end{array}$ \\
\hline \multicolumn{13}{|c|}{ Moderate shunt $\dagger$} \\
\hline Baseline & 1.95 & 15.5 & 2.0 & 7.23 & 1.53 & 4.1 & 6.1 & 0.67 & 188 & 7.41 & 81 & 50 \\
\hline$\pm \mathrm{SEM}$ & 0.12 & 1.0 & 0.5 & 1.10 & 0.28 & 0.1 & 0.2 & 0.01 & 8 & 0.02 & 2 & 2 \\
\hline Open & $2.62 \ddagger$ & $19.5 \ddagger$ & $3.5 \ddagger$ & 6.60 & $2.83 \ddagger$ & $3.4 \ddagger$ & 5.9 & $0.58 \ddagger$ & 191 & $7.40 \neq$ & 81 & 52 \\
\hline$\pm \mathrm{SEM}$ & 0.25 & 1.0 & 0.5 & 1.0 & 0.52 & 0.1 & 0.1 & 0.01 & 10 & 0.02 & 2 & 2 \\
\hline \multicolumn{13}{|l|}{ Large shunt§ } \\
\hline Baseline & 1.97 & 16.5 & 1.5 & 7.67 & 1.1 & 4.1 & 6.2 & 0.66 & 192 & 7.42 & 80 & 48 \\
\hline$\pm \mathrm{SEM}$ & 0.18 & 2.0 & 0.5 & 0.88 & 0.2 & 0.1 & 0.1 & 0.02 & 7 & 0.01 & 3 & 1 \\
\hline Open & $3.26 \ddagger$ & $26.5 \ddagger$ & $6.5 \ddagger$ & $6.30 \ddagger$ & $3.0 \neq$ & $3.1 \neq$ & 6.0 & $0.51 \ddagger$ & 227 & 7.42 & 82 & 51 \\
\hline$\pm \mathrm{SEM}$ & $0.29^{\circ}$ & 5.0 & $2.0^{\circ}$ & 1.27 & 0.2 & $0.3^{\circ}$ & 0.2 & 0.05 & 12 & 0.01 & 5 & 4 \\
\hline
\end{tabular}

* PBF, pulmonary blood flow; PAP, pulmonary aterial pressure; LAP, left atrial pressure; PVR, pulmonary vascular resistance; $\dot{Q}_{L}$, lung lymph flow; $C_{L}$, lung Iymph protein concentration; $C_{P}$, plasma protein concentration; $C_{L} / C_{P}$, lymph/plasma protein concentration.

$\dagger n=7$.

$\ddagger$ Different from baseline, $p<0.05$.

$\S n=3$.

Table 2. Lung fluid filtration in five lambs with elevated left atrial pressure*

\begin{tabular}{|c|c|c|c|c|c|c|c|c|c|c|c|c|}
\hline & $\begin{array}{c}\text { PBF } \\
(\mathrm{L} / \mathrm{min})\end{array}$ & $\begin{array}{l}\text { PAP } \\
\text { (torr) }\end{array}$ & $\begin{array}{c}\mathrm{LAP} \\
\text { (torr } \mathrm{L} / \mathrm{min} \text { ) }\end{array}$ & $\begin{array}{l}\text { PVR } \\
\text { (torr) }\end{array}$ & $\begin{array}{c}\dot{\mathrm{Q}}_{\mathrm{L}} \\
(\mathrm{mL} / \mathrm{h})\end{array}$ & $\begin{array}{c}\mathrm{C}_{\mathrm{L}} \\
(\mathrm{g} / \mathrm{dL})\end{array}$ & $\begin{array}{c}\mathrm{C}_{\mathrm{P}} \\
(\mathrm{g} / \mathrm{dL})\end{array}$ & $\mathrm{C}_{\mathrm{L}} / \mathrm{C}_{\mathrm{P}}$ & $\begin{array}{c}\mathrm{HR} \\
(\mathrm{bpm})\end{array}$ & $\mathrm{pH}$ & $\begin{array}{l}\mathrm{PaO}_{2} \\
\text { (torr) }\end{array}$ & $\begin{array}{l}\mathrm{PaCO}_{2} \\
\text { (torr) }\end{array}$ \\
\hline Baseline & 1.80 & 18.0 & 2.5 & 8.62 & 2.16 & 3.7 & 5.9 & 0.61 & 189 & 7.43 & 75 & 46 \\
\hline$\pm \mathrm{SEM}$ & 0.09 & 0.5 & 0.5 & 0.85 & 0.25 & 0.2 & 0.1 & 0.02 & 12 & 0.02 & 1 & 2 \\
\hline Elevated left atrial pressure & 1.78 & $19.5 \dagger$ & $4.0 \dagger$ & 8.78 & $2.60 \dagger$ & $3.5 \dagger$ & $6.0 \dagger$ & $0.57 \dagger$ & $216 \dagger$ & 7.41 & 75 & 48 \\
\hline$\pm \mathrm{SEM}$ & 0.10 & 1.5 & 0.5 & 0.90 & 0.25 & 0.1 & 0.1 & 0.02 & 16 & 0.02 & 1 & 3 \\
\hline
\end{tabular}

* Abbreviations same as in Table 1.

$\dagger$ Different from baseline, $p<0.05$. 
contrast to the lambs with an open shunt, lung lymph flow increased only $20 \%$ over baseline and the lymph:plasma protein concentration ratio decreased only $6 \%$ (Table 1 ).

Partial obstruction of the mitral valve caused a slight increase in heart rate, but no significant change in arterial blood gas tensions. Mean central venous $(5.0 \pm 0.5$ to $5.5 \pm 0.5$ torr $)$ and aortic ( $82 \pm 3$ to $82 \pm 3$ torr) pressures and hematocrit $(26 \pm 1$ to $26 \pm 1$ ) were also not affected.

\section{DISCUSSION}

In our experiments, opening the aorticopulmonary shunt increased pulmonary blood flow, pulmonary arterial and left atrial pressures, and the rate of lung lymph flow, although the concentration of protein in lymph relative to that in plasma decreased. If we assume that the concentration of protein in lymph collected from the caudal mediastinal lymph node approximates that in the pulmonary interstitium, then the measurement of lung lymph flow and the concentration of protein in lymph should provide a sensitive index of net transvascular movement of fluid and protein in the lung (6-9). Because we observed no change in systemic venous pressure, respiratory rate, or intrapleural pressure during our experiments that might otherwise increase systemic lymph contamination of the caudal mediastinal lymph node, we may conclude that increasing pulmonary blood flow by opening an aorticopulmonary shunt in the lamb increased the rate of transvascular fluid filtration in the lung and decreased the concentration of protein in the pulmonary interstitium $(10-12)$.

In each of our experiments, the increase in transvascular fluid filtration was accompanied by a reduction in the concentration of protein in the pulmonary interstitium, while both the rate of lung lymph flow and the concentration of protein in the lymph always returned to baseline immediately upon closing the shunt. These findings suggest that the sieving properties of the microvascular membrane were intact, leaving us with two possible explanations for the observed increase in transvascular fluid filtration in the lung: 1) the increase in pulmonary blood flow and pressure could have recruited previously unperfused vessels in the lung, increasing the number of sites available for fluid

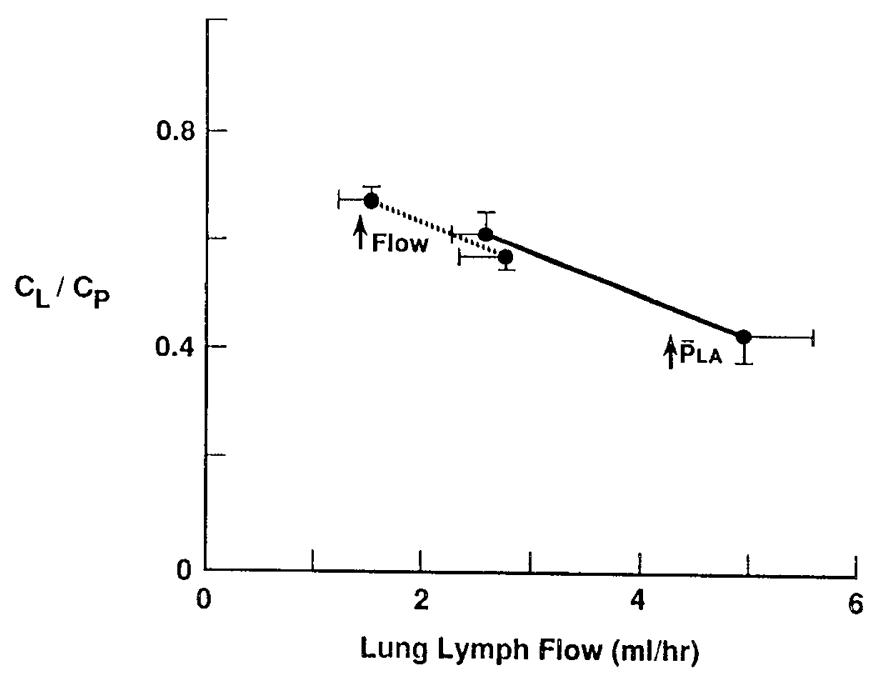

Fig. 1. Transvascular fluid filtration in lungs of young lambs. When the rate of lung lymph flow is increased by increasing microvascular pressure in the lung (increasing left atrial pressure, $\uparrow \overline{\text { Pla }}$ ) the lymph:plasma protein ratio decreases (12). The decrease in the lymph:plasma protein ratio seen with increasing lymph flow from increased blood flow (aorticopulmonary shunt, $\uparrow$ Flow) is virtually identical to that seen with increased microvascular pressure. $C_{\mathrm{L}} / C_{\mathrm{P}}$, lymph:plasma protein concentration ratio. exchange, or 2) the increase in pulmonary blood flow could have increased filtration pressure in the microvascular bed.

Could the results in our experiments be explained by recruitment of additional vessels in the lung? This is an important consideration because increased transvascular fluid filtration resulting from recruitment of vessels in the lung would be unlikely to result in an increase in extravascular lung water because lymphatics would presumably be recruited with blood vessels. The sieving properties of the newly recruited vessels in the lung should be similar to those of already perfused blood vessels, so that if the increase in lung lymph flow were the result of vascular recruitment, the concentration of protein in the lymph would not be expected to change. In our shunted lambs, the concentration of protein in lymph decreased with increasing lymph flow and the lymph to plasma protein concentration ratio decreased parallel to that seen in lambs with increased microvascular pressure (Fig. 1) (13).

If significant recruitment of pulmonary vessels had occurred in our experiments, pulmonary vascular resistance should have decreased as pulmonary blood flow increased by partially opening the shunt which it did not. Instead, we observed that pulmonary arterial pressure increased disproportionately to left atrial pressure. Taken together these results suggest that there was little vascular reserve in the lung of these newborn lambs and that little vascular recruitment occurred with increases in pulmonary blood flow from a large central shunt. These data are consistent with those reported by others suggesting that the lung of the newborn lamb is fully recruited at rest and that increasing microvascular pressure does not increase the vascular surface area of the lung (14-16).

The other possible explanation for the observed increase in transvascular fluid filtration is an increase in filtration pressure in the microcirculation of the lung. This hypothesis is supported by our observation of a decrease in the protein concentration in lymph relative to plasma with increasing lymph flow that was identical to that seen when filtration pressure was increased by increasing left atrial pressure (Fig. 1). If this were the case, what is the mechanism by which filtration pressure increases with increasing pulmonary blood flow? Left atrial pressure increased a small, but significant amount, when pulmonary blood flow increased and we wondered if this increase could account for the observed increase in the rate of lung lymph flow. To test this hypothesis we increased left atrial pressure in five lambs by an amount indentical to that seen with increased pulmonary blood flow. These experiments showed that increased left atrial pressure accounted for only a fraction of the increase in lymph flow and decrease in lymph protein concentration seen with increased pulmonary blood flow. We conclude, therefore, that the increase in filtration pressure was not solely the result of an increase in left atrial pressure.

Microvascular pressure could increase with increased flow if the resistance of the pulmonary vascular bed downstream from fluid filtering sites were relatively fixed (i.e. the downstream vessels are relatively nondistensible). This hypothesis is supported by our data showing that when pulmonary blood flow is increased, pulmonary arterial pressure increased more than left atrial pressure.

In a recent study, Teague et al. (17) increased pulmonary blood flow in lambs by creating peripheral arteriovenous anastomoses (bilateral carotid to jugular vein communication) and measured lung fluid filtration. They found that an $18 \%$ increase in pulmonary blood flow resulted in a $43 \%$ increase in the rate of lung lymph flow with no significant decrease in the lymph to plasma protein ratio and that pulmonary vascular resistance decreased. In addition, they found that when lung vascular pressures were increased by inflation of a balloon in the left atrium, that a $20 \%$ increase in pulmonary blood flow had no effect on lung lymph flow or the concentration of protein in lymph. They concluded that the increase in the rate of lymph flow with increasing pulmonary blood flow was the result of an 


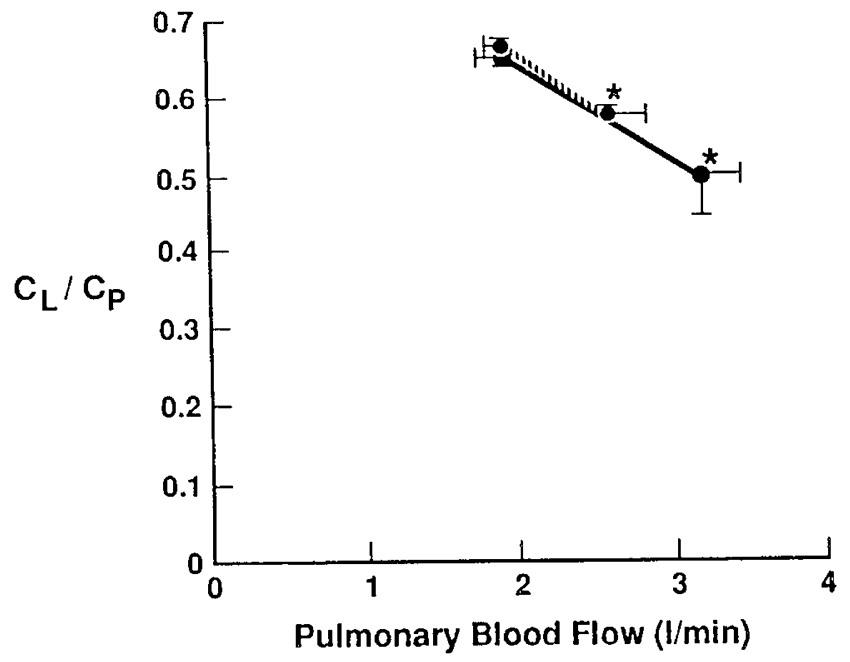

Fig. 2. The effects of increased pulmonary blood flow on the lymph:plasma protein concentration ratio $\left(C_{\mathrm{L}} / C_{\mathrm{P}}\right)$ in lambs with aorticopulmonary shunts. The $\mathrm{C}_{\mathrm{L}} / \mathrm{C}_{\mathrm{P}}$ ratio decreases with increased pulmonary blood flow from moderate (broken line) and large (solid line) aorticopulmonary shunts. The rate of decline in the $C_{L} / C_{P}$ with increased pulmonary blood flow was virtually identical in the two animal groups. * Significant change from baseline.

increase in vascular surface area, so that when the microvascular bed of the lung was fully recruited by increasing left atrial pressure, no further increase in surface area, hence lung lymph flow, could occur with increase in pulmonary blood flow.

There are two major differences between our study and that of Teague et al. (17). First, in our experiments, the shunt was central and undoubtedly caused some distension of the pulmonary artery. Distension of the pulmonary artery has been shown to increase vascular tone in downstream vessels and it is possible that such an increase in tone occurred in our experiments (1820 ). The lack of a significant decrease in pulmonary vascular resistance with increasing blood flow in our experiments supports this possibility. An increase in tone could prevent vessel recruitment and could fix the vascular resistance downstream from the fluid filtering sites in the lung. In defense of our methodology, the most important clinical cause of pulmonary edema in the premature newborn is a large central shunt, the patent ductus arteriosus.

Second, the increase in pulmonary blood flow in our lambs was nearly twice that seen in their experiments. It is possible that the increase in pulmonary blood flow in our experiments was so large that we obscured any small change in surface area that occurred. If this were the case, however, we might have expected the decrease in protein concentration in lymph with increasing lymph flow to have been somewhat blunted at lower compared to higher pulmonary blood flow rates. To the contrary, the decrease was almost identical to that seen with increased left atrial pressure and with much larger increases in pulmonary blood flow (Fig. 2).

We conclude, therefore, that increasing pulmonary blood flow by opening a large central shunt in the newborn lamb increases the rate of transvascular filtration of fluid by increasing filtration pressure. The increase in filtration pressure cannot be explained by increased left atrial pressure alone and suggests that resistance in vessels downstream to fluid filtering sites in the lung may be relatively fixed.

\section{REFERENCES}

1. Heymann MA 1983 Patent ductus areteriosus. In: Adams FH, Emmanouilides GC (eds) Moss' Heart Disease in Infants, Children, and Adolescents. Williams \& Wilkins, Baltimore, pp 158-170

2. Ellison RC, Peckham GJ, Lang P, Talner NS, Lerer TJ, Lin L, Dooley KJ, Nadas AS 1983 Evaluation of the preterm infant for patent ductus arteriosus. Pediatrics 71:364-372

3. Hirschklau MJ, DiSessa TG, Higgins CB, Friedman WF 1978 Echocardiographic diagnosis: pitfalls in the premature infant with a large patent ductus arteriosus. J Pediatr 92:474-477

4. Vick GW, Satterwhite C, Cassady G, Philips J, Yester MV, Logic JR 1982 Radionuclide angiography in the evaluation of ductal shunts in preterm infants. J Pediatr 101:264-268

5. Zar JH 1984 Biostatistical Analysis. Prentice-Hall, Inc, Englewood Cliffs, NJ

6. Nicolaysen G, Nicolaysen A, Staub NC 1975 A qualitative radioautographic comparison of albumin concentration in different sized lymph vessels in normal mouse lungs. Microvasc Res 10:138-152

7. Vreim CE, Snashall PD, Demling RH, Staub NC 1976 Lung lymph and free interstitial fluid protein composition in sheep with edema. Am J Physiol 230:1650-1653

8. Brigham KL, Woolverton WC, Blake LH, Staub NC 1975 Increased sheep lung vascular permeability caused by pseudomonas bacteria. J Clin Invest 54:792-804

9. Staub NC 1974 Pulmonary edema. Physiol Rev 54:678-811

10. Drake R, Adair T, Traber D, Gabel J 1981 Contamination of caudal mediastinal node efferent lymph in sheep. Am J Physiol 241:H354-H357

11. Roos PJ, Wiener-Kronish JP, Albertine KH, Staub NC 1983 Removal of abdominal sources of caudal mediastinal node lymph in anesthetized sheep. J Appl Physiol 55:996-1001

12. Drake R, Giesler M, Laine G, Gabel J, Hansen T 1985 Effect of outflow pressure on lung lymph flow in unanesthetized sheep. J Appl Physiol 58:7076

13. Hazinski TA, Bland RD, Hansen TN, Sedin EG, Goldberg RB 1986 Effect of hypoproteinemia on lung fluid balance in awake newborn lambs. $J$ Appl Physiol 61:1139-1148

14. Bland RD, McMillan DD 1977 Lung fluid dynamics in awake newborn lambs. $\mathrm{J}$ Clin Invest $60: 1107-1115$

15. Hansen TN, LeBlanc AL, Gest AL 1985 Hypoxia and angiotension II infusion redistribute lung blood flow in lambs. J Appl Physiol 58:812-818

16. Pitt BR, Lister G, Davies P, Reid L 1987 Correlation of pulmonary ACE activity and capillary surface area during postnatal development. J Appl Physiol 62:2031-2041

17. Teague WG, Berner ME, Bland RD 1988 Effects of pulmonary perfusion on lung fluid filtration in young lambs. Am J Physiol 255:H1336-H1341

18. Hyman AL 1968 Pulmonary vasoconstriction due to nonocclusive distention of large pulmonary arteries in the dog. Circ Res 23:401-413

19. Juratsch CE, Emmanouilides GC, Thibeault DW, Baylen BG, Jengo JA, Laks MM 1980 Pulmonary arterial hypertension induced by distention of the main pulmonary artery in conscious newborn, young, and adult sheep. Pediatr Res 14:1332-1338

20. Baylen BG, Emmanouilides GC, Juratsch CE, Yoshida Y, French WJ, Criley JM 1980 Main pulmonary artery distention: a potential mechanism for acute pulmonary hypertension in the human newborn infant. J Pediatr 96:540544 